\title{
POLITITIKK

\section{Sveriges säkerhetspolitiska förhållande med USA i en ny tid}

\author{
Erik Brattberg \\ McCain Institute for International Leadership
}

\section{Inledning}

När USA:s vicepresident Joe Biden besökte i Stockholm i augusti 2016 påpekade statsminister Stefan Löfven att »de svensk-amerikanska relationerna är bättre än någonsin.» Biden instämde och lade till att »vi får hemskt mycket gjort tillsammans.» (Regeringen, 2016). Liknande kommentarer gjordes även under President Barack Obamas Stockholms-besök i september 2013. Uttalanden som dessa är långt ifrån enbart diplomatiska artigheter utan illustrerar tydligt hur Sveriges relation med världens supermakt har stärkts under de senaste åren.

Det finns flera anledningar till detta inklusive aktiva bidrag till Nato-insatser såsom i Afghanistan och Libyen; gemensamma värderingar om demokrati, mänskliga rättigheter och öppenhet; ett omfattande underrättelsetjänst- och försvarsindustriellt samarbete; den ökade strategiska betydelsen av Östersjön efter Rysslands invasion av Krim 2014; samt president Obamas personliga intresse för den »nordiska modellen» som förebild.

Huruvida denna privilegierade ställning kommer fortskrida under den inkommande Trump-administrationen återstår dock att se. Troligtvis kommer Washington inta en mera skeptisk inställning till allierade och partnerländer i Europa, något som skulle kunna tvinga Sverige att se över sin försvarspolitik i grunden.

\section{Sveriges förhållande med USA: från kalla kriget till efter II september}

Sveriges diplomatiska relation med Washington har historiskt sett varit långt så självklar som den är idag. Neutraliteten under det andra världskriget bidrog till att Sverige efter kriget fokuserade på att upprätta en nordisk försvarsallians tillsammans 
med Danmark och Norge. När dessa istället valde att gå med i Nato kom Sverige att formellt hamna utanför västalliansen samtidigt som man ingick ekonomiskt, politiskt och kulturellt som en integrerad del av väst.

Trots att Stockholm officiellt såg sig själv som en neutral bricka mellan väst och östblocken under det kalla kriget så bedrev man i hemlighet ett nära samarbete med väst och framförallt USA. Detta samarbete har väl dokumenterats i journalisten Mikael Holmströms utmärkta bok» Den dolda alliansen» (Holmström, 2012). Här framgår att Sverige hade ett hemligt försvarsavtal med USA och betraktades i flera avseenden även som en de facto allierad av Washington som skulle understödjas vid ett eventuellt angrepp. Inom ramen för detta arrangemang bidrog Sverige med kunskap och underrättelseinformation om Sovjetunionen i utbyte mot annan information och särskilda garantier från USA och Nato. Det täta underrättelsesamarbetet med USA överlevde och har till och med utvecklas vidare sedan det kalla krigets slut.

Under Vietnamkriget var relationen mellan USA och Sverige särskilt ansträngd. Statsminister Olof Palmes högljudda kritik mot USA:s militära agerande i Vietnam vållade en diplomatisk kris mellan de båda huvudstäderna och ledde till att president Nixon till slut kallade hem sin ambassadör i Stockholm mellan åren 1968-1970. Efter Vietnam-krigets slut tinade dock relationerna upp.

Denna positiva utveckling fortsatte under Ingvar Karlsson och Carl Bildtregeringarna med flera besök av svenska ledare i Vita Huset. Efter kalla krigets slut har Sverige närmat sig USA och västalliansen samtidigt som den officiella nationella säkerhetsdoktrinen officiellt har rört sig från neutralitet till alliansfrihet. Viktiga milstolpar i denna process var Sveriges medlemskap i Natos partnerskap för fred 1994 och i EU det följande året. EU-medlemskapet och den svenska solidaritetsdeklarationen 2009 innebar ytterligare ett tydligt avstamp från den traditionella svenska neutralitetspolitiken.

Under 1990-talet kom Sverige att spela en roll i att stödja USA:s vision om ett »Europa helt och fritt». Framförallt så bidrog Sverige aktivt till Baltikums frigörelse från Sovjetunionen och sedermera återintegrering i den västliga gemenskapen. Sveriges politiska och ekonomiska stöd var avgörande för den succé som den baltiska återintegreringen i väst skulle komma att utgöra. Denna roll skulle fortsätta på 2000-talet då Sverige under utrikesminister Carl Bildt var en av initiativtagarna till EU:s östra partnerskapspolitik med stöd till länder som Georgien, Moldavien och Ukraina.

En svensk säkerhetspolitisk »normalisering» skedde också under denna tid med aktiva svenska truppbidrag till Nato-insatserna på Balkan under 1990-talet där svensk trupp för första gången lydde under Nato-kommando. Sverige genomförde också långtgående reformer av försvaret under 1990 och början av 2000-talet med syfte att skapa ett mindre och mera professionellt försvar fokuserat på »out of area» operationer. Denna omställning i svensk utrikespolitik välkomnades i Washington och skulle dessutom komma att ses som ett föredöme för andra europeiska länder under dessa år.

De förbättrade relationerna under 1990-talet fick dock ett bakslag i början av 2000-talet. Till skillnad från under Clinton-åren så stod inte Sverige lika högt i kurs 
i Washington under det tidiga 2000-talet. Även om president Bush besökte Göteborg 2001 under Sveriges EU-ordförandeskap rådde ett generellt ointresse mot Sverige i den amerikanska administrationen under det tidiga 2000-talet. Detta hade bland annat att göra med Bush-administrationens unilaterala fokus men också ointresse kring svenska prioriteringsfrågor såsom miljö och klimat. Svenska ambassaden hade under dessa år exempelvis upprepade svårigheter med att få till möten med högt uppsatta amerikanska tjänsteman. Efter 11 september gav Sverige helhjärtat stöd till kampen mot terrorismen. Likt så många andra europeiska länder bidrog dock Bushadministrationens invasion av Irak 2003 till att allvarligt anstränga de bilaterala relationerna med Washington under denna period.

Dock engagerade Sverige sig i återuppbyggnaden av Irak, bland annat genom att stå som värd för en FN-konferens på detta tema i maj 2008 med bland annat utrikesminister Condoleezza Rice som deltagare. Sveriges aktiva bidrag till ISAF-insatsen i Afghanistan efter 11 september-attackerna uppskattades också av Washington. Sverige kom sedermera att dessutom bli en betydelsefull bidragsgivare till utvecklingsinsatser i Afghanistan. Under flera år på 2000-talet utgjorde Afghanistan Sveriges enskilt största mottagarland av bistånd. Dessa och andra bidrag till FNinsatser skulle komma att flitigt citeras i Washington som ett föredöme för andra mindre europeiska länder om att ta på sig mera ansvar, eller »pull above their weight» som det ofta heter i Washington.

\section{Sverige och USA under Barack Obama}

Barack Obamas seger i presidentvalet 2008 välkomnades i Sverige liksom runtom i Europa. Under Obamas tid som president har de svensk-amerikanska förhållandena stärkts ytterligare. Hillary Clinton och John Kerry besökte båda Sverige under sina respektive perioder som utrikesministrar. I september 2013 gjorde Barack Obamas ett plötsligt nedstamp i Stockholm. Även om detta besök kom till efter att Obamas resa till Ryssland ställdes in efter Edward Snowden-affären så var det ingen tillfällighet att han besökte Sverige utan ett resultat av de starka förhållandena. Mera nyligen i augusti 2016 besökte även vice presidenten Joe Biden Stockholm. Grädden på moset var dock det nordisk-amerikanska toppmötet (»US-Nordic Summit») som hölls i Washington i maj 2016 och där alla de nordiska ledarna deltog.

För President Obama har Sverige setts som en förebild och partner i flera avseenden. Vita Huset uppskattade hur Sverige tillsammans med Tyskland visade exempel på starkt humanitärt ledarskap under 2015 års flyktingkris. Washington ser Sverige som en nära partner vad gäller frågor som humanitära insatser i omvärlden. Med USA som en av sina största handelspartners var Sverige en tidig och aktiv pådrivare för det transatlantiska handels- och investeringspartnerskapsavtalet (TTIP) mellan EU och USA vilket också uppskattades av Obama-administrationen. Det faktum att Sverige också har setts som en förebild i Vita Huset vad gäller frågor som exempelvis klimat och miljö, gender, innovation och grön teknologi har bidragit till att öka Washingtons intresse för Sverige. Dock har det även framkommit viss kritik mot 
Sverige från Washington. Exempelvis har Obama-administrationen uttalat sig kritiskt mot att Sverige inte motsätter sig byggandet av den ryska gasledningen Nord Stream II i Östersjön som delvis sträcker sig över svenskt territorialvatten. Obamas särskilda sändebud för anti-semitism har också varit på plats i Sverige för samtal om hur antisemitism i Malmö bättre kan bekämpas.

På det säkerhetspolitiska planet har Sveriges fortsatta bidrag till internationella fredsinsatser uppskattats av Washington. Under Libyen-operationen 2011 bidrog Sverige med sex Gripen-plan på spaningsuppdrag. Tillsammans med ISAFoperationen i Afghanistan bidrog denna insats till att stärka Sveriges roll som betydelsefullt partnerland för USA och Nato-alliansen. På Nato-toppmötet i Chicago 2012 fick dåvarande statsminister Fredrik Reinfeldt äran att inledningstala efter Barack Obama på ett toppnivåmöte. Sverige erhöll under Wales-toppmötet i september 2014 titeln »Enhanced Opportunities Partner» tillsammans med Finland och ett par andra länder. Tillsammans med sin finska kollega deltog också Stefan Löfven på middagen för Natos statschefer under toppmötet i Warszawa i juni 2016. I Washington har den svenska regeringens stöd till Ukraina och konsekventa hållning $i$ frågan om EU:s sanktioner mot Ryssland uppskattats liksom de svenska bidragen till anti-IS koalitionen i Irak.

Sveriges närmande till Nato och USA har dock inte varit helt okontroversiell i den svenska debatten. Kritik har framkommit mot Sveriges aktiva deltagande i USAledda militära operationer såsom i Afghanistan och Libyen. Somliga svenska debattörer ser sådana insatser som ett svek mot den traditionella neutralitetspolitiken. Från vissa håll hörs också kritik mot Nato som sådant och mot att Sverige deltar i gemensamma Natoövningar i Östersjöregionen eftersom dessa utmålas som provokativa mot Ryssland.

En annan central aspekt av Sveriges försvarspolitiska samarbete med USA är försvarsindustrin. Under kalla kriget var Sverige djupt beroende av överföring av amerikansk teknologi för att kunna upprätthålla sin egen försvarsindustriella bas. Även om Sverige hade en stor egen, relativt självförsörjande militärindustriellt komplex så var samarbetet med USA avgörande. Detta samarbete har fortsatt, och i flera avseenden ökat, efter kalla krigets slut. Det svenska försvarsföretaget Saabs Gripenplan tillverkas exempelvis med cirka 50\% USA-byggda komponenter. ${ }^{1}$ Saab har även inlett samarbete med Boeing om att ta fram ett gemensamt skolflygplan för det amerikanska luftförsvaret. Samarbete sker även inom andra högteknologiska områden och Sverige has dessutom ett MoU med USA om försvarsupphandling. ${ }^{2}$

\footnotetext{
${ }^{1}$ Den försvarspolitiska länken mellan Sverige/Norden och USA diskuteras i Michael Mohr och Erik Brattberg »U.S.-Nordic Defense Industry Cooperation: Adding Value to the Transatlantic Relationship», Daniel Hamilton et al. (ed.) Advancing U.S.-Nordic-Baltic Security Cooperation», Center for Transatlantic Relations, Washington DC, september 2014. Se även Magnus Nordenman »Of Eagles and Griffins: A View from Washington The Future of the US-Swedish Defense and Security Relationship», Kungliga Krigsvetenskapsakademins skrift, Nr.1 januari 2015.

${ }^{2}$ För en god överblick över hur Sverige och USA kan samarbeta för att stärka försvarsförmågan, se Magnus Nordenman, Enhancing the US-Swedish Defense Relationship», Atlantic Council, Issue Brief, oktober 2016.
} 
Dessutom är det långvariga underrättelsesamarbetet mellan amerikanska NSA och svenska FRA (Försvarets Radioanstalt) en annan viktig säkerhetspolitisk länk mellan Sverige och USA framförallt vad beträffar kunskap om Ryssland. Detta samarbete har dock nyligen vållat stark debatt på hemmaplan i Sverige i efterdyningarna av Snowden-avslöjarna. Trots detta fortskrider det praktiska samarbetet dock relativt oförändrat.

\section{Ryssland och situationen i Östersjön}

Den enskilt viktigaste anledningen till det ökade amerikanska intresset för Sverige är dock den allvarliga försämringen av säkerhetsläget i Östersjöregionen sedan Rysslands invasion och illegala annektering av Krim i mars $2014 .^{3}$ De ansträngda relationerna mellan Väst och Ryssland och det försämrade säkerhetsläget i Europa har som bekant även påverkat Sveriges egen säkerhetssituation sitt närområde. Skulle en konflikt med Ryssland uppstå i Östersjöregionen så skulle Sverige direkt komma att påverkas. Sveriges ökade utsatthet mot ryska intrång illustrerades exempelvis under den uppmärksammade ubåtsjakten i Stockholms skärgård under hösten 2014. Utöver de direkt militära hoten så har även Rysslands ökade användning av så kalla hybridkrigsföring ökat i regionen, inklusive propaganda, desinformation och cyberattacker (Kragh \& Åsberg, 2016) mot mål i Sverige.

Rysslands alltmer provokativa och aggressiva beteende i Östersjön har inneburit att Nato och USA behöver engagera sig mer i området för att kunna försvara de utsatta Nato-länderna i Baltikum och Polen. I och med att säkerhetssituationen i Östersjön allvarligt har försämrats de senaste åren har Sveriges relevans som strategisk partner till USA i närområdet sålunda stärkts. Förutom en starkare amerikansk militär närvaro i regionen krävs också ett förstärkt samarbete mellan Pentagon och icke-Nato länderna Sverige och Finland. Framförallt har Gotlands betydelse för förmågan att kunna försvara Baltikum vid en kris med Ryssland påvisats av flera studier. ${ }^{4}$ USA vill se ett aktiva svenska bidrag till den regionala stabiliteten i Östersjön och till avskräckningen av Ryssland. Ett centralt amerikanskt intresse är här förmågan att kunna utnyttja svenskt territorium vid en eventuell kris. Därav betydelsen av det värdlandsavtal (»host nation support agreement») som Sverige och Nato nyligen skrev under. Sverige har också ökat sitt deltagande i regionala övningar tillsammans med USA.

Under den nuvarande rödgröna regeringen har Sverige tagit ytterligare steg mot att närma sig Nato och USA. Det råder inte längre någon tvekan ens inom det socialdemokratiska partiet att USA och Nato spelar en central och avgörande roll för säkerheten i närområdet. ${ }^{5}$ Den så-kallade Hultqvist-linjen (döpt efter den socialde-

\footnotetext{
${ }^{3}$ För en bra överblick om diskussionen i Washington om Sveriges roll i säkerheten i Östersjön efter Kriminvasionen, se Katarina Traczs bok »Fredens hav? Ökade spänningar kring Östersjön», publicerad av Timbro Förlag, 2015.

${ }^{4}$ Se exempelvis https://www.cnas.org/publications/reports/assured-resolve-testing-possible-challengesto-baltic-security http://www.rand.org/pubs/research_reports/RR1253.html

${ }^{5}$ I Sverige har debatten om Nato-medlemskap samtidigt blossat upp sedan Kriminvasionen. Flera opinionsundersökningar visar att stödet har ökat.
} 
mokratiske försvarsministern Peter Hultqvist) innebär att Sverige bygger säkerhet genom att stärka olika säkerhetsnätverk, främst den »transatlantiska länken» med USA. Som en del av detta har Sverige och USA skrivit under ett memorandum om ökat försvarssamarbete som innebär ökat informationsutbyte, gemensamma militära övningar och samarbete kring utveckling av militära resurser (Defense News, 2016). För den svenska regeringen är denna typ av bilaterala samarbete med USA också avgörande för Sveriges egna territoriella säkerhet mot Ryssland. Det var därför som Joe Bidens uttalande om Sveriges territoriella »okränkbarhet» (Aftonbladet, 2016) fick stort utrymme i den svenska debatten och till och med tolkades av somliga svenska försvarspolitiska experter som en amerikansk säkerhetsutfästelse.

Samtidigt som Sverige har stärkt sitt samarbete med USA och Nato har förhållandet till Ryssland försämras. De diplomatiska kontakterna mellan Stockholm och Moskva har blivit betydligt kyligare sedan Krim-invasionen 2014. Sverige avstår numera från att delta i gemensamma militärövningar med Ryssland och har avbrutit en rad andra samarbeten. Både den borgliga regeringen ledd av Fredrik Reinfeldt och den nuvarande socialdemokratiska regeringen har dessutom konsekvent verkat för att behålla EU:s sanktioner mot Ryssland och att bistå Ukraina.

\section{Vad väntar Sverige under president Trump?}

Valet av Donald J. Trump till USA:s 45:e president kommer att påverka USA:s roll i Europa inklusive dess relation med Sverige. Skulle Hillary Clinton ha blivit vald så skulle vi sannolikt ha sett en fortsättning av Obama-administrationens politik i Europa. Istället ser vi nu ökad osäkerhet kring USA:s framtida ledarskapsroll inom Nato. Även om USA kommer fortsätta utgöra Europas centrala säkerhetsgarantör (eftersom det inte finns några andra alternativ) kan vi väl komma att se ett mindre engagerat och aktivt USA i Europa som samtidigt kanske försöker genomföra en diplomatisk omställning med Moskva vilket $\mathrm{i}$ sin tur kan få säkerhetspolitiska konsekvenser för Europa.

För Sveriges del innebär detta att förhållandet med USA kan komma att påverkas. Den nya Trump-administrationen kommer sannolikt vara mindre intresserade av traditionella mjuka svenska frågor såsom exempelvis multilateralism, miljö och gender. Den svenska modellen kommer heller inte längre ses som en förebild i samma utsträckning som under Obama och Sveriges generösa invandringspolitik kan till och med bidra till friktion i relationen med den nya administrationen i Washington. Ett automatisk amerikanskt intresse och goodwill gentemot Sverige (och Norden) kommer således inte gå att räkna med längre.

Trumps kritik mot Nato-ländernas otillräckliga försvarsutgifter drabbar också Sverige, det land i Östersjöregionen som spenderar procentuellt minst på sitt förvar (för nuvarande kring $1.1 \%$ av BNP). Det finns således en risk för att den nya administrationen kommer se Sverige som en »friåkare» och vara mindre intresserat av att samarbeta med Sverige. Eftersom Sverige står utanför Nato och har byggt sin nuvarande försvarspolitik på ett bilateralt samarbete med USA och Nato skulle en sådan utveckling vara högst problematisk. I dessa nya tider är det speciellt viktigt att 
Sverige hittar nya sätt att engagera och intressera den nya amerikanska administrationen. Ökade svenska bidrag till anti-IS koalitionen i Syrien och Irak kan bli ett potentiellt viktigt sätt att demonstrera relevans och relatera till den nya Trumpadministrationens agenda. Kraftigt ökade svenska försvarsutgifter ett annat.

Men även om de diplomatiska relationerna mellan Washington och Stockholm skulle bli mera ansträngda så kommer det tunga säkerhetspolitiska samarbetet dock sannolikt att bestå framöver. De diplomatiska förhållandena har testats under tidigare perioder utan att spilla över på det säkerhetspolitiska planet. En liknande utveckling kan bli fallet under de kommande fyra åren.

\section{Litteratur}

Aftonbladet: »Sverige okränkbart - punkt», 25 augusti 2016, http://www.aftonbladet.se/senastenytt/ttnyheter/ inrikes/article23405759.ab

Defense News, „Sweden, US Agree to Closer Defense Collaboration», 8 juni 2016, http://www.defensenews. com/story/defense/policy-budget/policy/2016/06/08/sweden-us-russia-hultqvist-intent/85573150/

Holmström, Mikael (2012) »Den dolda alliansen», Atlantisk Bokförlag.

Kragh, Martin \& Sebastian Åsberg (2017) »Russia's Strategy for Influence through Public Diplomacy and Active Measures: the Swedish case», fournal of Strategic Studies, januari 2017.

Regeringen (2016), http://www.government.se/press-releases/2016/08/prime-minister-stefan-lofven-to-receiveus-vice-president-joe-biden/

\section{Om forfatteren}

Erik Brattberg är svensk säkerhetspolitisk analytiker baserad i Washington och knuten till tankesmedjan McCain Institute for International Leadership. Korrespondens: brattberg.erik@gmail.com. 